\title{
LAS VOCES CHILENAS BAJO LA MIRADA BOLAÑIANA. NOTAS CRÍTICAS SOBRE CHILE Y SUS ESCRITORES: EL “INFIERNO” PERSONAL DE ROBERTO BOLAÑO
}

\author{
Valeria Bril \\ SECyT-UNC, Universidad Nacional de Córdoba, Argentina
}

\begin{abstract}
RESUMEN: La producción narrativa del escritor chileno Roberto Bolaño (1953-2003), quien realizó su carrera literaria en el extranjero, constituye una fuente de debate en la actualidad en el ámbito académico. Este trabajo se propone analizar de manera crítica la relación de Roberto Bolaño con su país natal: Chile, y con los escritores y los estudiosos chilenos, quienes a partir de sus elaboraciones teóricas suman aportes a las discusiones por la obra bolañiana. Nuestra propuesta plantea subrayar el diálogo que se produce entre Roberto Bolaño -desde su línea de pensamiento literaria- y los críticos y los narradores chilenos contemporáneos, teniendo en cuenta los parámetros específicos de producción del autor en el marco de las letras hispanoamericanas.
\end{abstract}

PALABRAS CLAVE: Roberto Bolaño, Chile, los escritores y los estudiosos chilenos, obra bolañiana, línea de pensamiento literaria, narradores chilenos contemporáneos.

\section{CHILEAN VOICES UNDER THE LOOK BOLAÑIANA. CRITICAL NOTES ON CHILE AND WRITERS: THE PERSONAL “HELL" OF ROBERTO BOLAÑO}

ABSTRACT: The narrative production of the Chilean writer Roberto Bolaño (1953-2003), who made his literary career abroad, is a source of debate today in the academic field. This paper intends to critically analyze the relationship of Roberto Bolaño with his native country: Chile, and with Chilean writers and scholars, who from their theoretical elaborations added contributions to the discussions by the bolañiana work. Our proposal aims to highlight the dialogue that occurs between Roberto Bolaño-from his literary line of thought-and critics and contemporary Chilean narrators, taking into account the specific parameters of production by the author in the context of Latin American literature.

KEYWORDS: Roberto Bolaño, Chile, Chilean writers and scholars, bolañiana work, literary line of thought, contemporary Chilean narrators. 


\section{Introducción}

El escritor chileno Roberto Bolaño (1953-2003) es una figura central en la escena literaria de los últimos años del siglo XX. La crítica académica y periodística lo ha identificado como un escritor notable, que intervino de manera radical en el panorama literario hispanoamericano de manera radical, particularmente en la literatura chilena, y que demostró con pasión un gran interés por las letras. Esta pasión lo lleva a la desmesura en el ejercicio de su vocación de escritor y en su amor por la literatura. Lo que impulsa a Bolaño a pensar que: "Cada escritor parece obsesionado en autopromocionarse, y la autopromoción o el arribismo, como todo el mundo sabe, no deja tiempo para nada más. Bueno, sí, deja tiempo para ser cobarde" (Matus 2001). El modo con el que algunos escritores enfrentan el oficio, perturba a Bolaño a tal extremo que decide no ir a todos los lugares ni a todos los viajes de promoción que lo invitan; Bolaño nunca quiso hacer la vida social que hacían otros escritores.

Roberto Bolaño fue un escritor que comenzó sin apoyo de editoriales ni de la crítica ni mucho menos de sus pares, los autores contemporáneos. Fueron los jóvenes escritores (poetas) los que creyeron en él. Esto queda claro al comprobar la complicidad que Bolaño mantuvo siempre con ellos en oposición a la actitud lapidaria con la cual enfrentaba a los escritores consagrados. Encontramos opiniones contrarias y contradictorias al respecto, y creemos necesario agregar el comentario de Andrés Neuman, quien escribió asumiendo una postura desde lo que cree que Bolaño afirmaría: "Si estoy solo en el desierto, parece profetizar Bolaño, entonces ese desierto es mío. Y así fue: se apropió de un espacio nuevo y gigantesco en el que no estaba nadie" (2008). Sospechamos que, al revisar primero la crítica, Bolaño no se apropió de un espacio solitario, nuevo y gigantesco, sino que construyó para sí un "nuevo" espacio. Bolaño fue un autor que intentó crear un espacio diferente para su obra, y en este sentido buscó posicionarse como escritor en un lugar alejado en relación a sus compatriotas.

El autor chileno comienza a tener repercusión mediática en los años noventa con la publicación de La literatura nazi en América (1996), y se vuelve conocida su trayectoria literaria que había comenzado veinte años atrás con dos libros de poemas: Reinventar el amor (1976) y la antología poética Muchachos desnudos bajo el arco iris de fuego (1979). En aquellos años, el Chile natal de Bolaño transitaba por un período de concertación política y socio-económica tras los diecisiete años de dictadura. Sus habitantes estaban desbordados en sus vidas íntimas: cotidianas, por el horror vivido en un país violento o violentado, por los crímenes cometidos durante la dictadura militar. 
El proceso dictatorial (1973-1990) dejó como saldo un escenario desvastado en diferentes órdenes de la vida social, e impactó de una manera profunda en los escritores y en su literatura. Esta situación produjo una crisis epistemológica que se logró visualizar con el inicio de la democracia. El discurso literario en general, y en el caso particular de la narrativa, fue trastocado desde las estructuras y los parámetros normales. La crítica literaria fue erradicada. Las ideas que los escritores pretendían expresar, aparecían como denuncias veladas para evitar la censura. Los narradores chilenos adoptaron la metáfora, como herramienta de trabajo, para cifrar en sus textos el mensaje de terror y angustia que querían transmitir a modo de revelación a sus lectores. Lo único que les quedaba a los narradores era una sensación infinita de desconsuelo luego de los acontecimientos vividos.

Algunos narradores, exiliados o autoexiliados, gozaban de cierta libertad al escribir desde lugares de enunciación distantes de aquellos acontecimientos políticos que cambiarían la realidad en el país. Mientras Chile se encontraba en una situación de transición, Roberto Bolaño, al igual que otros escritores chilenos como Isabel Allende y Luis Sepúlveda, producía desde España la mayor parte de su obra en una década: La pista de hielo (1993), Fragmentos de la Universidad Desconocida (1993), La senda de los elefantes (1994), El último salvaje (1995), Los perros románticos (1995), La literatura nazi en América, Estrella distante (1996), Llamadas telefónicas (1997), Los detectives salvajes (1998), Monsieur Pain (1999) reedición de La senda de los elefantes-, Amuleto (1999), Tres (2000), y Nocturno de Chile (2000).

La crítica chilena Patricia Espinosa describe la capacidad creadora del autor haciendo una analogía que puede resultar hiperbólica para aquel que no conoce la vasta obra de Bolaño:

Roberto Bolaño (1953) irrumpe en la literatura chilena como un enajenado. Una bestia que produce y produce textos notables, que se mueve entre la poesía y la narrativa, una máquina de ficciones, donde compitiendo consigo mismo cada obra parecería superar a la anterior (2003: 13).

Bolaño escribe con un desenfado que asusta y provoca admiración en otros escritores. El escritor Alberto Fuguet afirma que: "El que está haciendo algo distinto, that blows you away, es Roberto Bolaño. Siento que a mí me liberó después que hubo un momento en que me estaba sintiendo un poco ahogado aquí en Chile, cuando todo había que pensarlo cuatro veces" (García Corales 2007: 165). 


\section{El país natal: Chile}

Roberto Bolaño visitó Chile en cuatro oportunidades (1973, 1998, 1999 y 2000), y las últimas visitas a su país le trajeron polémicas y confrontaciones con sus colegas. A finales de $1998^{1}$, Bolaño vivió como un incidente extraño lo ocurrido en la casa de la escritora chilena Diamela Eltit, el episodio tuvo una gran repercusión negativa en el país a partir de los comentarios que el autor publicara en la revista Ajoblanco de Barcelona; Bolaño escribió una suerte de crónica sobre lo sucedido en la cena a la que fue invitado junto a su familia, en la casa de la escritora y su marido, el ministro socialista Jorge Arrate, portavoz del gobierno de Frei. Los detalles de la crónica que trascendieron, no tardaron en circular por Chile, provocando susceptibilidades de todo tipo por los comentarios del autor, que complicarían su siguiente viaje a ese país que estaba programado para diciembre de 1999.

La polémica cena con Eltit y Arrate impulsa a Bolaño a escribir dos textos: "El pasillo sin salida aparente" y "Literatura y exilio". Es en el primer texto, en el cual figura una serie de comentarios inadecuados para algunos involucrados; el autor se compromete con opiniones que adquieren rápidamente estado público por la utilización de cierto humor crítico muy característico del propio Bolaño al mencionar en algunos pasajes del texto: la clase social del barrio en donde viven los anfitriones, las dimensiones de la casa, el tipo de comida que se sirve en la cena, y además se hace referencia a su preocupación por la seguridad de su familia, cuando "una pandilla de nazis" (Bolaño 2004: 72): un grupo de personas simpatizantes ideológicamente y representantes de "Patria y Libertad" (grupo paramilitar, opositor al gobierno de Salvador Allende) irrumpe en la casa por la presencia del ministro Arrate. Bolaño menciona que hubo otros temas de conversación en la cena; se habló de los talleres literarios, de la situación política de Chile y de sus escritores.

De este modo, Bolaño incursiona en la idea que tiene sobre los escritores chilenos, los que son y los que quieren ser, los cuales no parecen tener remedio porque "los chilenos acuden a los talleres literarios (me da miedo pensar cuántos existen a lo largo de la República) con la misma disposición mental con la que algunos neoyorquinos acuden al psicoanalista" (2004: 73). El autor sostiene que los escritores en Chile, se encuentran en una situación desdichada, puesto que todo el mundo escribe como si fuera una reacción esquizofrénica por las paradojas de sangre, es decir, una consecuencia por la situación política de hostigamiento y recesión de de-

1. Roberto Bolaño llegó a Chile con su esposa e hijo (Carolina y Lautaro); el autor fue invitado por la Revista Paula para participar como miembro del jurado en su concurso de cuentos. 
rechos que afectó a los chilenos por casi dos décadas; éstas parecieran ser las razones, que entiende Bolaño, por las cuales emergen los escritores en ese país. El desencanto de Bolaño, por Chile y por los escritores, lo lleva a afirmar que éstos últimos poseen un destino de ruptura y de resquebrajamiento, y que es de esperarse ya que: "como se rompe todo en Chile, y en esto quizás resida el encanto del país, su fuerza: en la voluntad de hundirse cuando puede volar y de volar cuando está irremisiblemente hundido" (2004: 73).

En 1999, Roberto Bolaño fue invitado a Chile por la Feria del Libro, y su visita al país le trajo a Bolaño las repercusiones de su viaje anterior, con las esperadas interpelaciones de parte de los escritores chilenos y una parte de la prensa que criticó duramente sus opiniones vertidas en las columnas literarias, que escribió para un periódico español (en la revista Ajoblanco) con relación a su visita anterior. Sin embargo, Jovana Skármeta, relacionista pública de la Editorial Fernández de Castro, quien acompañó a Bolaño tres veces de las cuatro que el autor visitó Chile, declaró: "es una persona súper directa, por lo mismo las polémicas. Es sincero, como que ya fuera español desde el punto de vista de la forma de ser; no anda haciéndose el simpático" (Montesinos). Dos caras contrapuestas, y a la vez compensatorias, muestran el perfil de escritor de Bolaño, un escritor que se somete a la polémica que genera los vaivenes mediáticos en el mundo literario. Así, Bolaño afirma sin rodeos protocolares: "Me encantaría que en Chile me quisieran y no salieran imbéciles diciendo que no soy chileno. En este sentido no me deja indiferente una buena crítica, pero tengo la piel dura y sé aguantar golpes" (Andonie Dracos 2002).

Por bien intencionados que hayan podido ser los cambios en el comportamiento del autor chileno, como podemos observar en aquellas afirmaciones en donde aseguraba que: "Esta vez iré como un soldado rendido. Las manos en la nuca y diciéndole a todos “yo quiero ser amigo vuestro"” (Jösch 2000), estas afirmaciones fueron hechas un poco antes de concretarse su última visita a Chile (pensada para marzo de 2000), suponemos que no le alcanzaron esos cambios en razón de su temperamento, para sostener una relación quizás demasiado precaria que mantenía con sus compatriotas. Habida cuenta de esta relación, Bolaño cree que como sus enemigos "gratuitos" van aumentando en número, prefiere mantenerse en una postura literaria más abierta y afirma irónicamente: "Dejo que me plagien con total tranquilidad" (Matus 2001).

La actitud de Bolaño de oponerse constantemente a sus pares generó muchísimas polémicas que le valieron una serie de enemigos, algunos de ellos persistieron en sus opiniones personales a pesar de su desaparición física. Bolaño solía confrontar de una manera incansable con aquellos escritores que consideraba 
"malos escritores" tal es el caso de la autora de La casa de los espíritus (1982): Isabel Allende ${ }^{2}$; sobre ella, dijo: "Me parece una mala escritora simple y llanamente, y llamarla escritora es darle cancha. Ni siquiera creo que Isabel Allende sea escritora, es una 'escribidora"' (Pavón 2007: 8). Por su parte, la escritora chilena Isabel Allende contestó la agresión diciendo que "echó" una mirada a un par de sus libros y le aburrieron. Además Allende agregó cuando le preguntaron su opinión sobre Bolaño, luego de la muerte del autor: "No me dolió mayormente porque él hablaba mal de todos. Es una persona que nunca dijo nada bueno de nadie. El hecho de que esté muerto no lo hace a mi juicio mejor persona. Era un señor bien desagradable" (Pavón 2007: 8).

Continuando en esta línea de críticas, Bolaño arremete contra su compatriota Antonio Skármeta a quien considera un personaje de la televisión, y asegura que es incapaz de leer sus libros porque "ojear su prosa me revuelve el estómago" (Pavón 2007: 8). Bolaño sigue con sus declaraciones polémicas, las más duras descalificaciones las reciben los escritores Isabel Allende y Antonio Skármeta, y reconoce que:

La verdad es que una vez dije lo que pensaba de Skármeta y de Isabel Allende, en tanto escritores. [..] No me parecen candidatos muy representativos de lo que puede ser la literatura chilena, lo que alguna vez fue o pretende ser. Ni uno ni otro han hecho demasiados esfuerzos por hacer literatura (Andonie Dracos 2002).

A pesar de que Bolaño se sitúa en un territorio peligroso, desde el cual despliega ampliamente sus acusaciones en contra de los escritores chilenos, quienes le provocan una carga valorativa emocional negativa, termina convirtiéndose en el protagonista de la historia reciente de la literatura chilena de los últimos años. Pero la apuesta de Bolaño es otra, ya que rescata del parnaso chileno a Pedro Lemebel, "El rebelde por excelencia de mi generación" (Bolaño 2004: 89), y cree que ese personaje bien conocido en la escena local se caracteriza por: "En Lemebel está la dulzura, una sensación de fin de mundo y el resentimiento feroz: con él no hay medias tintas, su lectura requiere una inmersión en profundidad" (Bolaño 2004: 89).

2. Jorge Herralde, editor de Anagrama -sello en el cual fueron publicados la mayoría de los libros de Roberto Bolaño-, considera que: hay escritores canonizados por la crítica o por el mercado, o por ambos. En el caso de Isabel Allende es una escritora "supercanonizada" por el mercado, y que no le interesa en absoluto (Gras Miravet 2000: 39). 
El autor afirma que Lemebel es uno de los escritores más brillantes de Chile, y el mejor "poeta" de su generación, cuya vida es un ejemplo para los poetas; aunque como todos sabemos, Lemebel no escribía poesía. Bolaño agregó:

Travestido, militante, tercermundista, anarquista, mapuche de adopción, vilipendiado por un establishment que no soporta sus palabras certeras, memorioso hasta las lágrimas, no hay campo de batalla en donde Lemebel, fragilísimo, no haya combatido y perdido (2004: 76).

Ante todo, el autor chileno considera que la búsqueda de libertad y no de respetabilidad de Pedro Lemebel, provoca entre sus colegas procedentes políticamente de la derecha o de la izquierda una falta de comprensión de esas actitudes o esas virtudes del novelista. Bolaño da cuenta que "ese escritor marica, mi héroe, podía estar en el bando de los perdedores pero que la victoria, la triste victoria que ofrece la Literatura (escrita así, con mayúsculas), sin duda era suya" (2004: 65-66). Los desbordes existenciales de este personaje tan querido por Bolaño, llevan al autor a pensar que siempre quiso ser un escritor político de izquierda, pero esos escritores le parecían infames y aun "miserables como escritores" (Orosz 2001; Monthiel y Rebelde 2003).

El profesor Grínor Rojo estima que Roberto Bolaño podría haber estado vinculado políticamente (al menos reconoce cierta intención al respecto) con el MIR; Rojo dijo: "Me refiero con esta última expresión a la nueva izquierda chilena, a la castroguevarista, la del Movimiento de Izquierda Revolucionaria (MIR), convencida de la necesidad de probar a los revolucionarios en el fuego mismo de la revolución, y que es el equipo con el que el joven Bolaño da la impresión de haberse sentido más a gusto" (2004: 205).

En 1998, Bolaño reconoció en una entrevista que cuando decide volver a Chile en 1973: "A los veinte años vuelvo a Chile sólo a hacer la Revolución. Yo estaba por aquella época más bien en la extrema izquierda, cercano al MIR, pero mi ideología era trotskista. En realidad el MIR nunca tuvo buena relación con la política de los países del Este" (Escritores 1998); y, en 2003, Bolaño dijo en otra entrevista:

Sigo siendo de izquierda y sigo creyendo que la izquierda, desde hace más de sesenta años, mantiene en pie un discurso vacío, una representación hueca que sólo puede sonarle bien (esa catarata de lugares comunes) a la canalla sentimental. En realidad, la izquierda real es la canalla sentimental quintaesenciada (AP 2003). 
Creemos necesario observar que los cinco años que separan una entrevista de otra, permiten advertir una diferencia en las opiniones de Bolaño al percibir que sus palabras adquieren un tono más sentencioso y tajante; el autor siente un desprecio por los canallas políticos, que estafaron socialmente a los latinoamericanos (recordando las dictaduras militares). Siguiendo los acontecimientos políticos, que afectaron de manera social, económica y cultural, a Chile, es aquí donde surgen las relaciones obvias entre literatura y política. Cuando le preguntaron a Roberto Bolaño en una entrevista: qué le hubiera dicho a Salvador Allende ${ }^{3}$, el autor respondió que los que tienen el poder, aunque sea por poco tiempo, no saben nada de literatura sólo les interesa el poder, y afirmó: "Yo puedo ser el payaso de mis lectores, si me da la real gana, pero nunca de los poderosos. Suena un poco melodramático. Suena a declaración de puta honrada. Pero, en fin, así es" (Maristain 2003). Éstas son las declaraciones de un hombre maduro, convertido en un escritor con experiencia, que ha dejado de ser aquel joven poeta "ilusionado", que regresó a su país cuando tenía apenas veinte años de edad.

\subsection{Bolaño "extraterritorial"}

En algunos de los libros de Bolaño se puede observar cómo el autor elabora una relación entre su país natal y Latinoamérica, que establece a partir de la imagen del "infierno". Ejemplos de esta figuración los podemos encontrar en el cuento "Encuentro con Enrique Lihn" del libro de relatos Putas asesinas (2001), en donde el autor recrea ficcionalmente bajo una fuerte crítica velada los acontecimientos políticos ocurridos en Chile: "[...] en un país que bien pudiera ser Chile y en una ciudad que bien pudiera ser Santiago, si consideramos que Chile y Santiago alguna vez se parecieron al infierno y que ese parecido, en algún sustrato de la ciudad real y de la ciudad imaginaria, permanecerá siempre" (Bolaño, 2001: 217), y en el cuento "Carnet de baile" del mismo libro, se puede leer lo siguiente: "Pienso en los poetas muertos en el potro de tortura, en los muertos de sida, de sobredosis, en todos los que creyeron en el paraíso latinoamericano y murieron en el infierno latinoamericano" (215)

Conforme con ello, Bolaño vuelve a reflexionar sobre lo que sucedió en Chile, formulando las siguientes preguntas: ¿se puede tener nostalgia de la pobreza, de la intolerancia, de la prepotencia, de la injusticia?, ¿se puede tener nostalgia por la tie-

3. Bolaño estuvo en Chile, en la ciudad de Santiago, en 1973. Se reunió allí, con un grupo de jóvenes leales a Salvador Allende, para defender al depuesto presidente. 
rra en donde uno estuvo a punto de morir? Estas preguntas son las que intenta responder el autor en el texto: "Literatura y exilio"4, en donde insiste que la nostalgia de los latinoamericanos le suena a mentira. No obstante, comprende la nostalgia que puede sentir un político, pero no la de un escritor a quien considera un trabajador y para quien sus manos son su patria. Bolaño afirmó:

[...] mi abuelo era gallego y mi abuela catalana. Mi padre, que nació en Chile, se ha convertido en un mexicano. Mi familia o parte de ella es de clase obrera, y la clase obrera sólo necesita un empujoncito para dejar de creer en la patria, que es un invento burgués [...] Por otra parte tengo que aceptar que estoy casi siempre en contra de la mayoría y la patria es el lugar en donde la mayoría (los compatriotas) impone con mayor persuasión sus dogmas y sus castigos y sus premios (García 2001).

Bolaño fue un rebelde nato, y sabía que sus compatriotas no lo consideraban chileno, los mexicanos y los españoles no lo consideraban ni mexicano ni español, sin embargo dijo:

Yo me siento chileno. Es decir, no me siento de ningún país, pero sé que soy chileno porque tengo un pasaporte chileno y tengo una única nacionalidad que es la chilena... he leído cosas que me han llegado de Chile donde se dice que difícilmente se me podría considerar chileno (Soto 1998).

Ciertamente, el autor siempre supo que era un latinoamericano, cuya patria estaba radicada en su vocación de ser escritor; en palabras de Bolaño: "Para el escritor de verdad su única patria es su biblioteca que puede estar en estanterías o dentro de su memoria" (2004: 43). Siguiendo la lógica del autor, éste amplía sus opiniones al respecto: "Una obra poética suele ser el resultado de una biblioteca y de una vida, de los saltos y sobresaltos de esa vida. [..] no sólo quiero decir viajes y riesgos sino también enfermedades, amistades, hechos mínimos y cotidianos" (García 2001). Aunque Bolaño afirmó en boca de uno de sus personajes, el cura Sebastián Urrutia Lacroix (seudónimo H. Ibacache), en la novela Nocturno de Chile: "para qué sirven los libros, son sólo sombras" (2000: 64), son estas "sombras" las que indefectiblemente convirtieron a Bolaño en un escritor que está a la altura de "quienes con la uña del índice eran capaces de rascar la superficie de escritos" (Bolaño 2000: 123).

4. El texto "Literatura y exilio" fue leído el 3 de abril de 2000 en el marco del Simposio sobre "Europa y América Latina: literatura, migración e identidad”, organizado por la Sociedad Austríaca para la Literatura de Viena. 
Bolaño convertido en un escritor capaz de demostrar su talento a partir de un trabajo constante que involucra un arduo sacrificio por su vocación literaria, y a pesar de sostener teóricamente que: "la literatura es una rareza" (2000: 14) y convivir con este modo de pensar la literatura, ocupa un lugar complejo de discernimiento para la crítica; Bolaño es un autor muy cuestionado para bien o para mal en los debates actuales, pero es sin duda la figura más sobresaliente de las letras hispanoamericanas.

En rigor de verdad, Bolaño nos tiene acostumbrados a su modo diferente de ver la vida y la literatura, y por algunos de sus gestos podemos advertir que el autor chileno parece olvidar lo que escribió en una de sus últimas novelas: "lo importante era la vida, no la literatura" (Bolaño 2000: 138). La afirmación del autor queda plasmada casi como un absurdo, ya que se convocaban a reuniones culturales-literarias (tertulias) en Chile mientras se torturaban a personas en los sótanos. En Nocturno de Chile se hace referencia a este oscuro episodio de la historia chilena, en donde el protagonista Sebastián Urrutia Lacroix acepta tal situación, inclina su cabeza y se aleja del lugar, pensando:

Así se hace la literatura en Chile, pero no sólo en Chile, también en Argentina y en México, en Guatemala y en Uruguay, y en España y en Francia y en Alemania, y en la verde Inglaterra y en la alegre Italia. Así se hace la literatura. O lo que nosotros, para no caer en el vertedero, llamamos literatura (Bolaño 2000: 147).

La literatura que "hacen" los escritores en Chile, como en otros países en los que se han vivido situaciones de extrema violencia político-social, es una literatura cuyo origen se presenta como oscuro por ser una literatura "manchada con sangre" y silenciada por el toque de queda. Por eso el desprecio y el dolor que Bolaño experimenta ante esos acontecimientos, tendrán un papel fundamental en su obra, en donde los recupera como si fueran partes de un ejercicio para la memoria. Conforme a este propósito, Bolaño utiliza los mecanismos que le proporciona la llamada "literatura oficial", esa literatura que tanto odiaba Bolaño: "El desprecio que sentía por la así llamada literatura oficial era enorme, aunque sólo un poco más grande que el que sentía por la literatura marginal" (2002: 10). El autor exhibe en su modo de "hacer literatura" los atributos especiales que esta posee, estos atributos no son compatibles con el arribismo y el oportunismo con los cuales algunos escritores ejercen el oficio.

Bolaño quiso expresar su propio pensamiento a través de su literatura, pensamiento que trasciende a su práctica de escritura al proyectarse como parte constitutiva de su narrativa, que logra comunicar desde el lugar de extranjeridad del autor, que es posible franquear las fronteras gracias a su ética literaria. Bolaño no 
es un extranjero o un exiliado, o un autoexiliado, sino que es un autor latinoamericano, que escribe desde la autoexploración para trazar con vehemencia un nuevo estilo literario. Ignacio Echevarría (amigo y albacea de Bolaño) considera que el escritor manifiesta: "una estrategia de exilio permanente" (Pinto 2003), que es un elemento esencial en su narrativa. En dos entrevistas, Bolaño ${ }^{5}$ procuró sintetizar lo que para él significa su condición de chileno, y dijo: "[... soy chileno, es algo con lo que vivo con mayor o menor resignación, pero ese ser chileno no me remite, necesariamente, a lo que, casi siempre con poca fortuna, se da en llamar patria. Y si viviera en Chile me sentiría en el extranjero" (Aguilar 2002); y en otra entrevista, afirmó: "Curiosamente nunca me he sentido exiliado. [..] Lo que sí me he sentido es extranjero, pero extranjero me he sentido en todas partes, empezando por Chile. Como fui un niño pedante, ya desde niño me sentía extranjero" (Carvajal 2003).

El autor vivió muchos años en México, porque su familia se trasladó al Distrito Federal cuando Bolaño tenía quince años, y luego viajó a España en donde decidió residir de manera permanente; sin embargo no se considera un exiliado ${ }^{6}$. En este sentido, el crítico literario Javier Edwards refuerza la idea sobre el sentimiento que tienen algunos exiliados o autoexiliados con relación a la patria, y reflexiona:

Algo queda de las raíces, siempre quedan raíces, pero resulta pretencioso que al cabo del tiempo el país los reclame como propios y se los atribuya cada vez que se hace mención de ellos. Bolaño es chileno en su partida de nacimiento, y en la fuerza polémica que ha mostrado en sus visitas o en libros como Nocturno de Chile donde hace rendir cuentas al mundillo literario local (Espinosa 2003: 119).

Por su parte Roberto Contreras, otro chileno, escribe:

Es la recuperación personal como lector de un sentido de la narrativa que hace tiempo no se veía/leía en habla hispana. Menos en un chileno. Sospecho que eso me hizo seguir leyéndolo: reconocer que de momentos hablaba perfectamente de nosotros. Mejor que nosotros mismos. Me ganó la acidez de su mirada y la suciedad de su escritura. "Realismo a ultranza", pensé (Espinosa 2003: 208).

5. Bolaño respondió sobre la definición de "la chilenidad" en una entrevista, pero que había mencionado en otra entrevista, y aclaró: "No recuerdo esa entrevista. Probablemente, como siempre, dije muchas tonterías. A mí me trae al fresco la definición de la chilenidad. Tampoco me interesa la definición -el fijar fronteras, cuando la naturaleza de las fronteras es naturalmente difusa- de la americanidad, ni de la españolidad, ni de la occidentalidad" (Pinto 2001).

6. En una entrevista, Bolaño afirmó: "[..] yo jamás me he sentido un exiliado en España, como tampoco me sentí un exiliado en México, ni en Centroamérica, ni en ningún otro lugar en donde se hablara español" (García 2001). 
Contreras percibe a Bolaño como un escritor chileno, y a partir de ello analiza su obra. Esta mirada crítica la podemos encontrar en otros académicos chilenos, quienes poseen una actitud o una percepción de análisis que se puede visualizar como una apropiación de la figura de Roberto Bolaño como chileno, e incluso registramos que se insiste en contextualizar al autor en la escena literaria chilena. Pero, reconocemos que en Chile, hay excepciones, es el caso de Manuel Jofré quien dijo:

Me alegro que Bolaño no tenga país. Su nación son las letras y su patria los cuestionamientos. Nada que quepa muy cerca de nosotros. Para nosotros, todos los discursos que nos rodean son complacientes y si asentimos, se nos dará lo que debemos.

Esta literatura de Bolaño funciona de otra manera. No quiere saber de los chilenos, sus porquerías lo ofuscan, los temas nacionales le revientan. Chile no es nada más que un tópico negativo en la literatura de Bolaño. El país es algo que le revienta, que le choca, que no le gusta (Espinosa 2003: 238).

De todos modos, las posteriores variaciones de reflexiones en torno a la identidad de la literatura de Bolaño a partir de la nacionalidad del autor, incorporan sentidos críticos diversos, algunos válidos, para estudiar la obra bolañiana, pero la mayoría de ellos deberían ser percibidos como construcciones subjetivas por los intereses que entran en juego en los escenarios literarios locales. En este punto, y coincidiendo con lo que señaló Alejandro Zambra, quién señaló que: "Lo que sí he descubierto (aunque ya lo sabía) es que a los chilenos nos gusta demasiado que a los españoles les guste Bolaño" (Espinosa 2003: 258), se hace necesario precisar que la extranjería de Bolaño parece ser una condición de su escritura, y con arreglo a la cual se convierte en un procedimiento, un punto de partida para narrar algo que quiere contar el autor. Bolaño fue un extranjero errante, que se dedicó a escribir en sus horas libres cuando trabajaba como cuidador en un camping o vendedor de bisutería, y sus personajes son fieles reflejos de su autor, puesto que no tienen patria y sus vidas transcurren sin rumbo definido.

En la extensa producción literaria de Roberto Bolaño encontramos temas recurrentes relacionados con las andanzas de los poetas, la búsqueda de escritores, y los grupos o los movimientos literarios, y entre sus personajes predilectos se hallan las figuras de escritores, algunos reales (auto) exiliados y otros ficticios, que son propios de la imaginación del autor; pero sobre todo observamos una celebración constante de la literatura.

\subsection{La "verdadera" Patria de un escritor}

La patria de un escritor es su lengua y su memoria, y otras veces puede ser su lealtad y su valor. Según Bolaño: “[..] mi patria es mi hijo y mi biblioteca. Una bi- 
blioteca modesta que he perdido en dos ocasiones, con motivo de dos traslados radicales y desastrosos, y que he rehecho con paciencia" (2004: 44).

$\mathrm{El}$ autor reconoce que tanto la patria como el exilio tienen connotaciones particulares, que generan deseos que no siempre se corresponden con el sentido común o con la realidad. Bolaño piensa que el exilio es una opción literaria similar a la escritura: nadie te obliga a irte de tu país, así como nadie te obliga a escribir. De esta manera, Bolaño considera que: "El escritor entra voluntariamente en ese laberinto, por múltiples razones, claro está, porque no desea morirse, porque desea que lo quieran, etc., pero no entra forzado [..]" (2004: 55).

Huelga señalar que Bolaño menciona, en una doble apuesta, que el escritor puede trabajar, a diferencia de otras profesiones, en el lugar en donde se encuentra ubicado, y fuera de su país pareciera que se desarrollara aún más. Bolaño afirma: "El escritor es y trabaja en cualquier situación" (2004: 56), y su oficio se parece al de: "Las putas, tal vez, sean las que más se acercan al oficio de la literatura" (2004: 56).

Bolaño explica en el "Discurso de Caracas" que: "En realidad muchas pueden ser las patrias de un escritor, a veces la identidad de esta patria depende en grado sumo de aquello que en ese momento está escribiendo" (Manzoni 2002: 211). La definición de "patria" de Bolaño, en el discurso que mencionamos, coincide con el texto "Literatura y exilio", escrito en 2000; pero se observan algunas diferencias por cambios en la opinión del autor, en una de sus últimas entrevistas, concedida en el otoño de 2002: "Sobre la vida y la obra. Conversación con Roberto Bolaño", en dicha entrevista Bolaño habló sobre la única patria de un escritor. Para Bolaño, las "patrias" corresponden a un solo pasaporte que es la calidad de la escritura, pero ello no significa escribir bien o maravillosamente bien ya que esto lo puede hacer cualquiera. En consecuencia, el autor definió lo que es una escritura de calidad: "Pues lo que siempre ha sido: saber meter la cabeza en lo oscuro, saber saltar al vacío, saber que la literatura básicamente es un oficio peligroso" (Manzoni 2002: 211). Pero, en efecto, Bolaño que no supo separar la ficción de su autobiografía, modificó su modo de pensar la patria. Acaso la presunción del autor sobre la patria está ligada al avance de su enfermedad, y al hecho de querer conjurar, de una vez y para siempre, sus demonios personales:

Durante mucho tiempo se dijo -yo lo dije- que la única patria de un escritor era su lengua. Ya no lo creo. Tampoco creo que mi patria sea mi literatura ni la literatura. Más bien diría que mi patria es mi vida, es decir que mi patria es algo frágil y débil e insignifícate. También podría decir, siguiendo esta línea, que estoy exiliado de mi patria y que vivo en la patria de los otros, como emigrante sin papeles, y que procuro no molestar ni estar demasiado tiempo en un lugar (Donoso 2004). 
Esas consideraciones creemos que apelan a la intención que guarda el autor de fundar una explicación, que recae en el concepto de que la literatura siempre vive a través del escritor; por lo que Bolaño afirma que "pueden salir unos equívocos espantosos": "unos egos hipertrofiados" o "una literatura aquejada de raquitismo" (Donoso 2004). Las distinciones que Bolaño lleva a cabo sobre la literatura, y principalmente sobre la literatura chilena, se presentan alejadas de las elecciones que versan sobre sus gustos personales, y se basan en lo que considera el autor la posesión o la falta de conocimiento del oficio de escritor. Bolaño afirmó: "En un país como Chile, donde hasta los expertos en poesía no tienen ni idea de qué es un dímetro coriámbico, resulta peligroso definirse como poeta" (Pinto 2001). El autor inicia un ajuste de cuentas con su país natal a partir de postular sus propias verdades literarias, quedando inmerso en un proceso lúdico de dimes y diretes, con sus compatriotas, del cual no pudo o no quiso despegarse durante su vida literaria.

El autor español Enrique Vila Matas, citando a César Aira, hace referencia al tipo de escritor que prevalece en nuestro fin de siglo pasado, que es el llamado "escritor gentleman" (1999), un profesional que no confunde los libros con su persona. Se puede suponer que, a diferencia de Aira, Vila Matas se considera más cercano a la figura de escritor que propone Bolaño: un escritor que se define en la extravagancia por no querer tener pasaporte y preferir una vida nómada. Estas rarezas literarias constituyen rasgos que poseen aquellos escritores en los que la vida y la literatura parecen no poder existir por separado. La sintonía con esta clase de escritores, que es oportuno señalar como pertinente para la figura de Bolaño, cuyos gustos y rechazos literarios forman claramente un punto de vista en sus literaturas, terminan definiendo a este grupo, en el cual se encuentra Bolaño, como escritores "extraterritoriales" con relación a lo que propone el universo literario como aceptable y previsible.

Siguiendo la reflexión sobre lo que es la literatura y el oficio de escritor, le preguntaron a Roberto Bolaño en varias oportunidades: si él mismo y su historia de vida no se habían transformado en proyecto literario, y si siendo un creador de personajes no se había inventado como autor. Bolaño respondió que no creía que se pudiese inventar a sí mismo como escritor, pero existía la posibilidad de que: "Te inventen, es posible, a hachazos, en una o dos ocasiones a lo largo de toda tu vida" (Donoso 2004), y puede ocurrir que: cuando estés dando una lección es muy probable que seas en realidad quien está recibiendo la lección. En este caso, Bolaño subraya el perfil de un escritor situado a partir de la inversión de roles, en el lugar de aprendiz (en la vida y), en el oficio de la literatura. 


\section{Bibliografía}

AGUILAR, G. (2002). "La literatura se instala en el territorio de las colisiones y los desastres". Entrevista a Roberto Bolaño" <http://www.garciamadero.blogs pot.com/.../la-literatura-se-instala-en-el.html>. (Acceso 16 Febrero 2007).

ANDONIE DRACOS, C. (2002). "Prefiero a la Allende que a Teitelboim" $<$ http://www.letras.s5.com/bolano140802.htm>. (Acceso 24 Enero 2008).

AP (2003). "Falleció el escritor chileno Roberto Bolaño"<http://www.lanacion. com.ar/511598-fallecio-el-escritor-chileno-roberto-bolano.htm>. (Acceso 9 Julio 2007).

BOLAÑO, R. (1976). Reinventar el amor. México: Taller Martín Pescador.

BOLAÑO, R. (1993). Fragmentos de la Universidad Desconocida. Talavera de la Reina: Editorial Gráficas del Tajo.

BOLAÑO, R. (1993). La pista de hielo. Barcelona: Seix Barral.

BOLAÑO, R. (1995). El último salvaje. México: Al Este del Paraíso.

BOLAÑO, R. (1995). Los perros románticos. San Sebastián: Fundación Social y Cultural Kutxa.

BOLAÑO, R. (1996). Estrella distante. Barcelona: Anagrama.

BOLAÑO, R. (1996). La literatura nazi en América. Barcelona: Seix Barral.

BOLAÑO, R. (1997). Llamadas telefónicas. Barcelona: Anagrama.

BOLAÑO, R. (1998). Los detectives salvajes. Barcelona: Anagrama.

BOLAÑO, R. (1999). Amuleto. Barcelona: Anagrama.

BOLAÑO, R. (1999). Monsieur Pain. Barcelona: Anagrama.

BOLAÑO, R. (2000). Nocturno de Chile. Barcelona: Anagrama.

BOLAÑO, R. (2000). Tres. Barcelona: Acantilado.

BOLAÑO, R. (2001). Putas asesinas. Barcelona: Anagrama.

BOLAÑO, R. (2002). Amberes. Barcelona: Anagrama.

BOLAÑO, R. (2004). Entre paréntesis. Barcelona: Anagrama.

BOLAÑO, R. (2004). "Tres discursos insufribles. Discurso de Caracas" en Entre paréntesis. Barcelona: Anagrama.

BOLAÑO, R. (2004). "Tres discursos insufribles. Literatura y exilio" en Entre paréntesis. Barcelona: Anagrama.

BOLAÑO, R. y SANTIAGO, M. (1979). Muchachos desnudos bajo el arcoíris de fuego. México: Extemporáneos.

CARVAJAL, A. (2003). "Extranjero me siento en todas partes" <http://eltiempo. terra.com.co/hist_imp/HISTORICO_IMPRESO/cult_hist/2003-01-03/AR TICULO-WEB-NOTA_INTERIOR_HIST-241656.html>. (Acceso 22 Agosto 2008). 
CONTRERAS, R. (2003). "Roberto Bolaño (Santiago, 1953)" en Territorios en fuga. Estudios críticos sobre la obra de Roberto Bolaño. (Comp. Patricia Espinosa H.). Santiago: Frasis Editores.

DONOSO, P. (2004). "Sobre la vida y la obra. Conversación con Roberto Bolaño" $<w w w . d e r i v a . o r g / e n t r e v i s t a s / e n t r e v i s t a s . p h p ? I D=5>$. (Acceso 5 Marzo 2009).

EDWARDS, J. (2003). "Roberto Bolaño, escritor para leer" en Territorios en fuga. Estudios críticos sobre la obra de Roberto Bolaño. (Comp. Patricia Espinosa H.). Santiago: Frasis Editores.

ESCRITORES (1998). "Entrevista a Roberto Bolaño" <http://www.escritores.cl/ bolanoentrev.htm>. (Acceso 8 Junio 2006).

ESPINOSA, H.P. (2003). Territorios en fuga. Estudios críticos sobre la obra de Roberto Bolaño. Santiago: Frasis Editores.

GARCÍA CORALES, G. (2007). El debate cultural y la literatura chilena actual. Un diálogo con cinco generaciones de escritores. Lewiston: The Edwin Mellen Press.

GARCÍA, L. (2001). "Entrevista a Roberto Bolaño" <http://www.critica.cl.htm>. (Acceso 10 Abril 2009).

GRAS MIRAVET, D. (2000). "Entrevista con Roberto Bolaño”. Cuadernos Hispanoamericanos (604): 53-65.

ALLENDE, I. (1982). La casa de los espíritus. Barcelona: Plaza \& Janés.

JOFRÉ, M. (2003). "Bolaño: romantiqueando perros, como un detective salvaje" en Territorios en fuga. Estudios críticos sobre la obra de Roberto Bolaño. (Comp. Patricia Espinosa H.). Santiago: Frasis.

JÖSCH, M. (2000). "Roberto Bolaño: 'Esta vez iré con las manos en la nuca"” $<$ http://www.tercera.cl/diario/2000/02/25/t-25.40.3a.CUL.BOLANNIO.html>. (Acceso 8 Febrero 2009).

MANZONI, C. (2002). Roberto Bolaño: la escritura como tauromaquia. Buenos Aires: Ediciones Corregidor.

MARISTAIN, M. (2003). "La última entrevista de Roberto Bolaño: Estrella distante" http://www.pagina12web.com.ar/suplementos/radar/vernota.php?id_ nota $=843 \&$ sec $=9 . h t m>$. (Acceso 4 Mayo 2008).

MATUS, A. (2001). "Dejo que me plagien con total tranquilidad" <http://www.le tras.s5.com/bolano1811.htm>. (Acceso 12 Noviembre 2004).

MONTESINOS, E. "Roberto Bolaño: el peligro de la escritura" < http://www.le tras.s5.com/robbolano1508.htm>. (Acceso 28 Marzo 2011).

MONTHIEL, D.F. y REBELDE, C. (2003). "El detective salvaje" <http://www.re belion.org/hemeroteca/cultura/030821detective.htm.>. (Acceso 20 Octubre 2009). 
NEUMAN, A. (2008). "Las tres apariciones de Bolaño" <http://www.clarin.com/ notas/2008/11/15/_-01802130.htm>. (Acceso 2 Diciembre 2010).

OROSZ, D. (2001). "Siempre quise ser un escritor político" $<$ http://www.lavoz delinterior.com/2001/1226/suplementos/cultura/nota73286_1.htm>. (Acceso 22 Setiembre 2007).

PAVÓN, H. (2007). "La leyenda del gran escritor”. Ñ Revista de Cultura IV (208): 6-9.

PINTO, R. (2001). "Bolaño a la vuelta de la esquina" <http://www.letras.s5.com/ bolao1.htm>. (Acceso 11 Noviembre 2007).

PINTO, R. (2003). "Bolaño y la generación perdida de América Latina" $<$ http://www.proyectoespartaco.wordpress.com/.../bolano-y-la-generacionperdida-de- america-latina.htm>. (Acceso 21 Octubre 2009).

ROJO, G. (2004). "Bolaño y Chile". Anales de Literatura Chilena 5 (5): 201-211.

SOTO, M. (1998). "Yo me siento chileno'. Entrevista a Roberto Bolaño" $<$ http://www.garciamadero.blogspot.com/.../yo-me-siento-chileno-entrevistaroberto.html>. (Acceso 15 Agosto 2008).

VILA-MATAS, E. (1999). "Bolaño en la distancia" <http://www.letraslibres. com.htm>. (Acceso 5 Junio 2009).

ZAMBRA, A. (2003). "Una novela pendiente" en Territorios en fuga. Estudios críticos sobre la obra de Roberto Bolaño. (Comp. Patricia Espinosa H.). Santiago: Frasis Editores. 
